REVISTA DE LA CEPAL 87 • DICIEMBRE 2005

\title{
Hacia una política de innovación eficiente en América Latina
}

\author{
William F. Maloney y Guillermo Perry
}

L.

innovación se ha convertido en un tema central en la agenda de crecimiento de América Latina. Este artículo examina cuatro interrogantes: ¿Cómo podemos saber si tras el deficiente desempeño regional de la productividad total de los factores hay realmente un "problema de innovación”? ¿Qué queremos decir cuando hablamos de innovación y cuáles son los aspectos en los que la región acusa deficiencias? ¿Qué recomiendan la experiencia y los estudios recientes en materia de principios y medidas de política para fomentar la innovación? ¿Existe algún vínculo entre las deficiencias señaladas y la equidad? Como ni siquiera en la Organización de Cooperación y Desarrollo Económicos (OCDE) hay consenso acerca de las políticas concretas que deberían aplicar los gobiernos, y aún menos respecto a si ellas son adecuadas para los países en desarrollo, este trabajo procura organizar la reflexión en torno a algunos principios básicos y dar a conocer algunas experiencias indicativas, más que entregar recomendaciones de política. 


\section{I}

\section{Introducción}

Los encargados de formular las políticas en América Latina han introducido el tema de la innovación en la agenda de políticas por diversas razones. En primer lugar, pese a dos décadas de amplias reformas estructurales, las tasas de crecimiento de la región han sido más bien modestas. Como casi la mitad de las diferencias de ingreso y crecimiento entre los países corresponden a diferencias en la productividad total de los factores, la escasa expansión de esta última en los países de América Latina y el Caribe durante los tres últimos decenios es motivo de inquietud. Aunque en el fondo esto es medida de nuestra ignorancia, las diferencias de productividad total de los factores suelen atribuirse a lo que en términos generales se denomina "progreso tecnológico" y más ampliamente a la "innovación" (incluidos los cambios técnicos, institucionales, orgánicos y administrativos y el desarrollo de actividades, productos y servicios nuevos tanto a nivel de la empresa como de la economía en general). En segundo lugar, gran parte del debate acerca de la competitividad se relaciona con la productividad y, en consecuencia, tiene mucho que ver con el tema de la innovación.

Por último, el hecho de que en la región persista un modelo de exportaciones basado en los recursos naturales lleva a preguntarse de dónde podrían surgir otras líneas de productos - recuérdese la evolución en Finlandia del gigante forestal Nokia hacia la producción de teléfonos celulares- y si podríamos lograr mejores resultados con lo que tenemos. Respecto de esto último, en una de las publicaciones emblemáticas del Banco Mundial ${ }^{1}$ se sostiene que los estudios recientes y la experiencia de numerosas economías actualmente desarrolladas pero que se han basado en los recursos naturales, indican que posiblemente Prebisch fue demasiado pesimista: los recursos naturales no son ni una maldición ni el destino que debemos perseguir obligadamente. En ese trabajo, nuestra conclusión principal fue que la región no estaba creciendo todo

Una versión preliminar de este trabajo fue presentada en el seminario "Economic growth with equity: challenges for Latin America" realizado en la CEPAL (Santiago de Chile, 1 y 2 de septiembre del 2005).

${ }^{1}$ De Ferranti, Perry, Lederman y Maloney (2002). lo que habría podido a través de la explotación de sus recursos naturales, en parte por los hoy conocidos inconvenientes de la industrialización mediante la sustitución de importaciones, que castigaba a estos sectores, pero quizá fundamentalmente por la falta de conocimientos y de capacidad innovadora de los países. A la larga, es posible que la disposición de América Latina a depender pasivamente de la transferencia de tecnología del extranjero y a no invertir lo suficiente en destrezas e investigación y desarrollo ( $\mathrm{I}+\mathrm{D})$ haya sido un aspecto de la dependencia muchísimo más perjudicial que otros que han sido más objeto de estudios.

De ahí que, al igual que en la OCDE, con frecuencia cada vez mayor quienes formulan las políticas en América Latina y el Caribe encuentran que la principal dificultad con que se tropieza para impulsar el crecimiento y el desarrollo son las barreras al comercio y la falta de incentivos para innovar. A fin de "hacer realidad un espacio europeo del aprendizaje permanente", durante la reunión del Consejo Europeo realizada en Barcelona en marzo del 2002 se acordó aumentar el gasto global en investigación y desarrollo de 1,9\% a 3\% del PIB en el 2010, para acortar las distancias con los Estados Unidos y Japón, cuyo gasto era de 2,7\% y $3 \%$ del PIB, respectivamente (OCDE, 2004). El 0,4\% de América Latina se halla en un nivel muy diferente (De Ferranti, Perry, Guasch y otros, 2003).

El presente estudio retrocede un paso y examina cuatro temas. En primer lugar, si el comportamiento deficiente en materia de productividad total de los factores en la región obedece a un "problema de innovación". Segundo, lo que queremos decir cuando hablamos de innovación y cuáles son los aspectos que presentan fallas. Tercero, si hay alguna relación entre estas deficiencias y el tema de la equidad, que fue examinado también en el seminario al que se presentó una primera versión de este trabajo. Y por último, qué aconsejan la experiencia y los estudios recientes respecto de los principios y medidas generales de política para fomentar la innovación. Dada la falta de consenso acerca de políticas concretas y de su aplicabilidad en los países en desarrollo, hemos organizado la reflexión en torno a algunos principios básicos y pretendemos dar a conocer experiencias más que ofrecer recomendaciones en materia de políticas. 


\section{II}

\section{¿Enfrentan los países de América Latina un problema de innovación?}

El problema de la innovación es especialmente delicado, puesto que la teoría sobre el tema abunda en ejemplos de fallas del mercado que conducen inevitablemente a atribuirle funciones al gobierno. En una región que históricamente se ha preocupado de las fallas del gobierno, la idea de que el mercado no está generando suficientes inversiones en innovación puede significar que en cierta medida se invierta la tendencia de los últimos 20 años a reducir la importancia de la política pública en la economía. Por lo tanto, para apreciar si el costo de las actuales fallas del mercado efectivamente supera el costo de las fallas potenciales de los gobiernos al aplicar determinadas políticas de innovación, es importante comprender la magnitud del problema que la innovación plantea.

Entre otros análisis, el trabajo de De Ferranti, Perry, Guasch y otros (2003) sugiere que, conforme a medidas comunes en materia de innovación y productividad, los países de América Latina y el Caribe van muy a la zaga de los países de comparación. Según los estándares de la OCDE, la región exhibe bajos niveles tanto de inversión en I+D como de participación en ella del sector privado, poca producción de patentes, y un peso relativo de la investigación básica mayor que el de la investigación aplicada. Sus resultados también son deficientes comparados con los estándares internacionales de calidad de la educación y de los recursos humanos dedicados a la I+D. Estos rezagos se mantienen cuando se miden en función del ingreso per cápita.

$\mathrm{Si}$ bien es cierto que estos datos son indicativos, no bastan para demostrar si tenemos o no un problema de innovación, y ello por varias razones. En primer lugar, los diagnósticos relativos a la innovación a menudo operan como si la acumulación de conocimientos, es decir, de capital cognitivo, fuera una actividad libre e independiente de otros factores que influyen en el grado de desarrollo de un país. Pero esto no es así: a nivel global, hay una fuerte relación positiva entre la productividad total de los factores y la razón entre capital y trabajo, lo que indica que la acumulación de capital cognitivo complementa las fuerzas que determinan la acumulación de capital físico y es impulsada por muchas de ellas (Maloney y Rodriguez-Clare, 2005). A su vez, esto nos lleva a preguntarnos si la insuficiencia de innovación que se percibe en un país es consecuencia de los problemas propios de la acumulación en general, o si la actividad de innovación misma se ve de alguna manera obstaculizada por fallas específicas del mercado, institucionales o de política.

Esta probable complementariedad también lleva a pensar que cualquier debate orientado a promover la innovación debería darse en un ambiente propicio para fomentar la acumulación en general. Como precedente de este enfoque amplio cabe mencionar el enfoque dicotómico que se está aplicando en Nueva Zelandia - mejorar la educación y la infraestructura de ciencia y tecnología, pero al mismo tiempo acentuar el apoyo a la iniciativa privada, la política de competencia y el estímulo para que la isla "salga de sí misma" y exporte- lo que generalmente da lugar a la exigencia de innovar. Muchos países latinoamericanos enfrentan un reto similar, y debido al reducido tamaño de sus mercados internos y a la distancia que los separa de otros más grandes se asemejan más a Nueva Zelandia que a España o Italia, países que al integrarse a la Unión Europea aumentaron su exposición a las fuerzas de la competencia, a otras formas de hacer negocios y a mercados más amplios. El peligro que encierra no adoptar este criterio es que la política de innovación pase a ser una actividad seductora pero aislada, desligada de la tarea menos atractiva de investigar las razones por las cuales a las empresas en general puede faltarles dinamismo.

Sin embargo, incluso una vez considerada la acumulación de capital humano y físico, los países de América Latina aún parecen tener un problema de innovación. Maloney y Rodriguez-Clare (2005) presentan un modelo calibrado que nos permite concluir que, dado el nivel de acumulación de capital humano y físico, la productividad total de los factores de muchos países de la región es relativamente reducida y la actividad innovadora enfrenta barreras implícitamente elevadas. Al parecer Chile, país cuyos datos examinaron esos autores con especial meticulosidad, tiene un problema de innovación, además de un problema general de acumulación. 
Cabe advertir que el modelo calibrado no puede distinguir entre problemas de innovación y otras ineficiencias que hacen disminuir la productividad total de los factores. Para explicar las deficiencias en esta materia, los estudios recientes realizados en Chile y otros lugares han hecho hincapié en la importancia del costo de los ajustes microeconómicos. Caballero, Cowan y otros (2004) sostienen que la flexibilidad microeconómica es el meollo de la destrucción creativa, del aumento de la productividad y del crecimiento económico y que las rigideces pueden ser muy costosas. Centrándose en la legislación laboral, calculan los efectos de la seguridad en el empleo en el período 19801998, utilizando una muestra de 60 países, y concluyen que el hecho de aumentar la seguridad en el empleo reduce en un tercio la velocidad de ajuste a las perturbaciones y disminuye casi en $1 \%$ el aumento de la productividad (en países en que impera el orden jurídico, entre ellos Chile). Caballero, Cowan y otros (2004) van aún más lejos, y sostienen que la desaceleración del aumento de la productividad registrada en Chile después de 1997 se debió en gran medida a un aumento de la rigidez microeconómica y que esta podría llegar a reducir anualmente en un $0,5 \%$ el crecimiento estructural a largo plazo.

Aunque el argumento es de peso, hay varios indicios de que el problema de la innovación continúa siendo un elemento muy importante para explicar las deficiencias de la productividad total de los factores y el lento crecimiento.

En primer lugar, si atribuyéramos el desfase de la productividad total de los factores únicamente a los costos de ajuste, el modelo calibrado de Maloney y Rodriguez-Clare indica que, dadas las amplias reformas microeconómicas realizadas en Chile hasta la fecha, sorprende la magnitud de las ineficiencias si se compara con los Estados Unidos.

Segundo, la historia sugiere que la falta de capacidad de innovación de los países ha sido un importante obstáculo para el crecimiento de América Latina en la posguerra. ${ }^{2}$ De Ferranti, Perry, Lederman y Maloney (2002) ofrecen varios ejemplos al respecto, entre los cuales Chile tal vez sea el más ilustrativo. En el caso de la minería chilena, Pinto (1959) sostuvo que

\footnotetext{
${ }^{2}$ Para una descripción más detallada de estos argumentos, véase Maloney (2002).
}

las empresas mineras locales no se ocuparon de aprender por la práctica en las etapas de explotación de baja tecnología y que, en consecuencia, enfrentadas a la revolución tecnológica, las compañías mineras locales no disponían de suficientes recursos acumulados ni de la capacidad orgánica o administrativa indispensable; en estas circunstancias, no les quedaba otra opción que introducir capital y destreza técnica extranjeros. Meller (2001) describe la forma en que la situación tecnológica de Chile continuó deteriorándose: en el decenio de 1950 se podría haber aprendido más sobre el cobre chileno en las bibliotecas extranjeras que en las chilenas. Tampoco se capacitaba a ingenieros y técnicos chilenos especializados en el cobre. Recién en 1965 Chile desarrollaría suficiente capacidad interna para analizar el papel que desempeñaba el cobre y formar profesionales y técnicos chilenos en la gestión de las grandes empresas cupríferas. Mientras tanto, el desarrollo de una amplia aglomeración minera en Australia y el lugar ocupado por la Universidad de Nueva Gales del Sur como principal formadora de ingenieros de minas del mundo tal vez explique por qué fueron ellos, y no los chilenos, quienes descubrieron la mina La Escondida, pese a que Chile comenzó a exportar cobre mucho antes que Australia. Wright (2001) cree detectar que el inadecuado aprovechamiento de los recursos naturales en Perú y otros países mineros encubría problemas de innovación. Otros ejemplos de México y Brasil que se examinan en De Ferranti, Perry, Lederman y Maloney (2002) muestran la importancia de la capacidad de innovación tanto para aprovechar las ventajas comparativas existentes como, es de suponer, para descubrir otras nuevas.

Por último, aunque el argumento de que "todos los demás lo están haciendo" no es en sí decisivo, resulta sugerente que países comparables como España y Nueva Zelandia (este último un país cuya trayectoria de reformas se aproxima mucho a la de los países latinoamericanos), estén focalizándose en la innovación como elemento fundamental de su futuro crecimiento.

Ciertamente, estos puntos de vista sobre el origen de la insuficiente productividad total de los factores son totalmente compatibles. La solución de los problemas relacionados con el ajuste microeconómico debe constituir el núcleo de la agenda de innovación, interpretado en términos generales como el aumento de la capacidad de las empresas para introducir medidas orientadas a aumentar su productividad. 


\section{III}

\section{¿Qué tipo de innovación les falta a los países latinoamericanos?}

Aunque los estudios a menudo se valen de la I+D como una variable sustitutiva convenientemente disponible de las actividades de innovación, tanto a nivel global como al de las empresas, no está claro qué medidas de innovación habría que considerar. Pese a lo mucho que se ha escrito sobre la importancia de la I+D para la adquisición de conocimientos y la transferencia de tecnología, la diferencia entre adopción e invención hace pensar que la I+D tal vez tenga menor importancia para los países menos avanzados que para los más avanzados. Incluso en la OCDE, algunos observadores sostienen que el papel de la I+D es reducido si se le compara con el que corresponde a la introducción de nuevas prácticas de organización y de gestión. ${ }^{3}$ Cabe entonces preguntarse cuáles son los componentes de una

\footnotetext{
${ }^{3}$ Por ejemplo, Comin (2004) sostiene que en los Estados Unidos se puede atribuir a I+D menos de 3 a 5 décimas de un punto porcentual de la tasa de crecimiento anual de la productividad de $2,2 \%$.
}

buena estrategia de innovación para que la productividad total de los factores aumente. Es más, también habría que preguntarse si todas las fórmulas encaminadas a acrecentar los actuales niveles de ingreso ofrecen bases igualmente sólidas para que en el futuro los ingresos aumenten. Las respuestas a estas preguntas sin duda influyen en la forma en que medimos las deficiencias en materia de innovación y en que focalizamos las políticas.

Un primer vistazo al uso de cuatro ingredientes de la transferencia de tecnología que se mencionan comúnmente, ajustados según el grado de desarrollo, nos lleva a algunas conclusiones interesantes (Maloney, 2005b). El gráfico 1 muestra que la I+D sube marcadamente a lo largo del proceso de desarrollo, que hay una varianza apreciable en torno a esta tendencia, y que los países de América Latina generalmente se sitúan por debajo de ella. El otorgamiento de licencias y la educación terciaria evolucionan de manera similar, aunque menos marcada, y al respecto los resultados de la

GRÁFICO 1

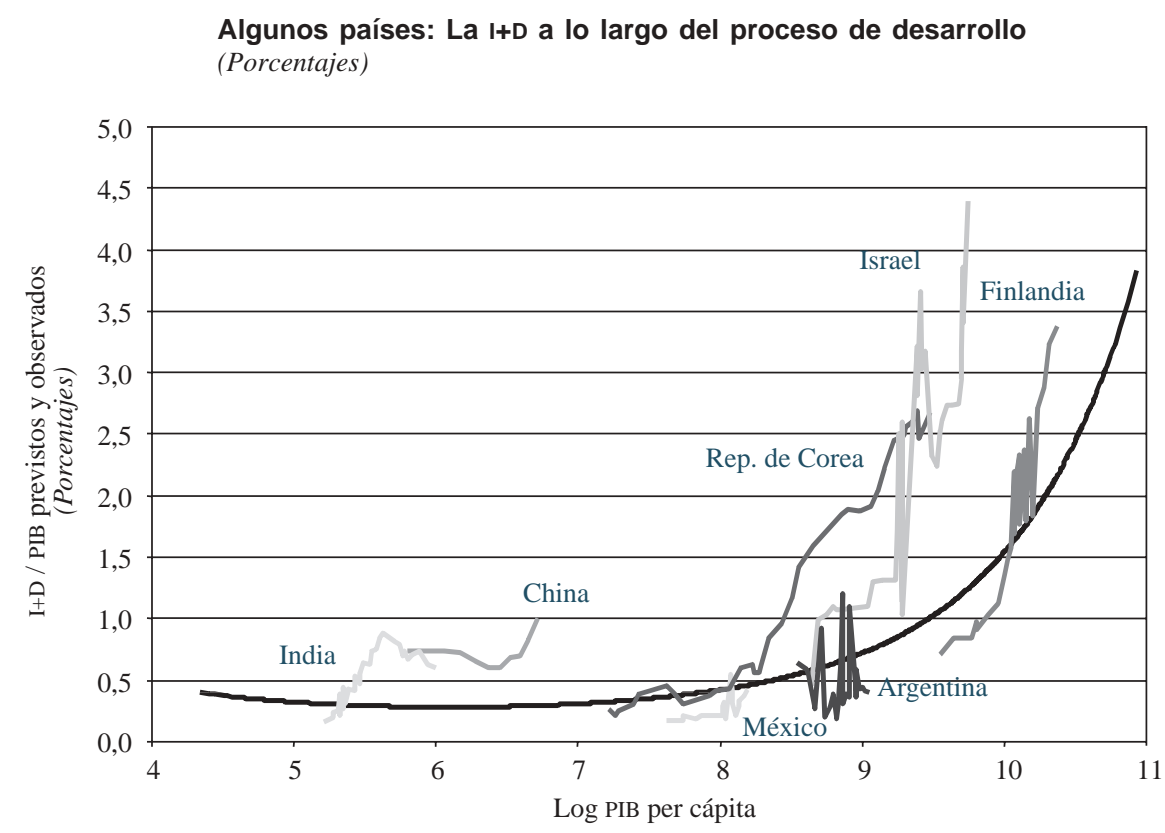

Fuente: Lederman y Maloney (2003). 
región son más dispares. Sin embargo, al igual que con los indicadores incondicionales que se utilizan generalmente, es preciso ser cautelosos al usar también estos indicadores para diagnósticos sobre la innovación. La teoría estándar del crecimiento postula que, lo mismo que las inversiones físicas, las inversiones en innovación lleva la producción a su nivel estacionario. De ahí que las inversiones en innovación no puedan considerarse medidas de desempeño, sino más bien fórmulas para lograr el nivel de ingresos observado. Desde el punto de vista estricto de la eficiencia, el alto nivel de inversión en I+D de China que se observa en el gráfico 1 posiblemente revele alguna afición a elefantes blancos tecnológicos. Lo que parece menos plausible es que la baja proporción de gente con educación terciaria que se registra en América Latina pueda revelar un uso ultraeficiente de esos recursos escasos. No hay duda de que la estructura económica - el hecho de que América Latina y el Caribe se especialice en la producción de bienes que en promedio tienen un bajo coeficiente de innovación medido, por ejemplo, en función de la I+D como proporción del valor agregado- también influye en los comportamientos que vemos. ${ }^{4}$ De todas formas, cabe formular dos observaciones al respecto.

Primero, los países latinoamericanos de América Latina y aquellos considerados milagros tecnológicos han empleado fórmulas muy diferentes en materia de I+D, inversión extranjera directa, licencias y educación. Finlandia y la República de Corea dependieron muy poco de la inversión extranjera directa y en forma marcada de la I+D y de las licencias de tecnología extranjera, modelo que está aplicando China. En parte, esto refleja la especialización de dichos países en productos electrónicos que tienen un coeficiente especialmente elevado de I+D. En cambio, América Latina ha apli- cado una fórmula consistente en una escasa dependencia de la I+D y de las patentes y una marcada dependencia de la inversión extranjera directa. Esta conclusión podría ser preocupante, debido a la baja tasa de transferencia de tecnología a través de la inversión extranjera directa de que dan cuenta numerosos autores y, con mayor razón aún, dada la general pasividad con que se aprovechan los beneficios tecnológicos de dicha inversión. En México, por ejemplo, pese a 30 años de presencia de las empresas Івм у нр en Guadalajara, no hay muchos indicios de que haya surgido una aglomeración de empresas en torno al conocimiento informático, al menos de acuerdo con los datos de que se dispone sobre el otorgamiento de patentes (gráfico 2).

No obstante que suele citarse como modelo para la región, la fórmula aplicada por Irlanda, que depende mucho del otorgamiento de licencias, es sui generis y deriva de su posición excepcional como puente de habla inglesa entre los Estados Unidos y la Unión Europea, condiciones que difícilmente pueden darse en América Latina. Lo más sorprendente es que España (y también Italia, que no figura en el gráfico) parece estar aplicando la fórmula latinoamericana y no se ha empeñado mucho en materia de I+D o de obtención de licencias para alcanzar niveles de ingreso relativamente elevados. En los últimos 30 años, ha llegado rápidamente a los niveles de ingreso de países de vanguardia y representa una alternativa importante respecto de las economías de reciente industrialización de Asia como punto de referencia para los países latinoamericanos. Esto indica que hay grandes posibilidades de incrementar la productividad total de los factores a partir de fuentes distintas de I+D: por ejemplo, de la introducción de innovaciones en el campo de la organización y la gestión (Caselli y Tenreyro, 2004). ${ }^{4}$ Como el estudio se realizó en torno al ingreso y no a la produc-
tividad total de los factores, esto podría indicar que el aumento del ingreso dependió de una alta acumulación no vinculada a la innovación. 
GRÁFICO 2

Algunos países: Desviaciones desde la tendencia para cuatro indicadores de adopción de tecnología y capacidad, entre 1972 y 1998
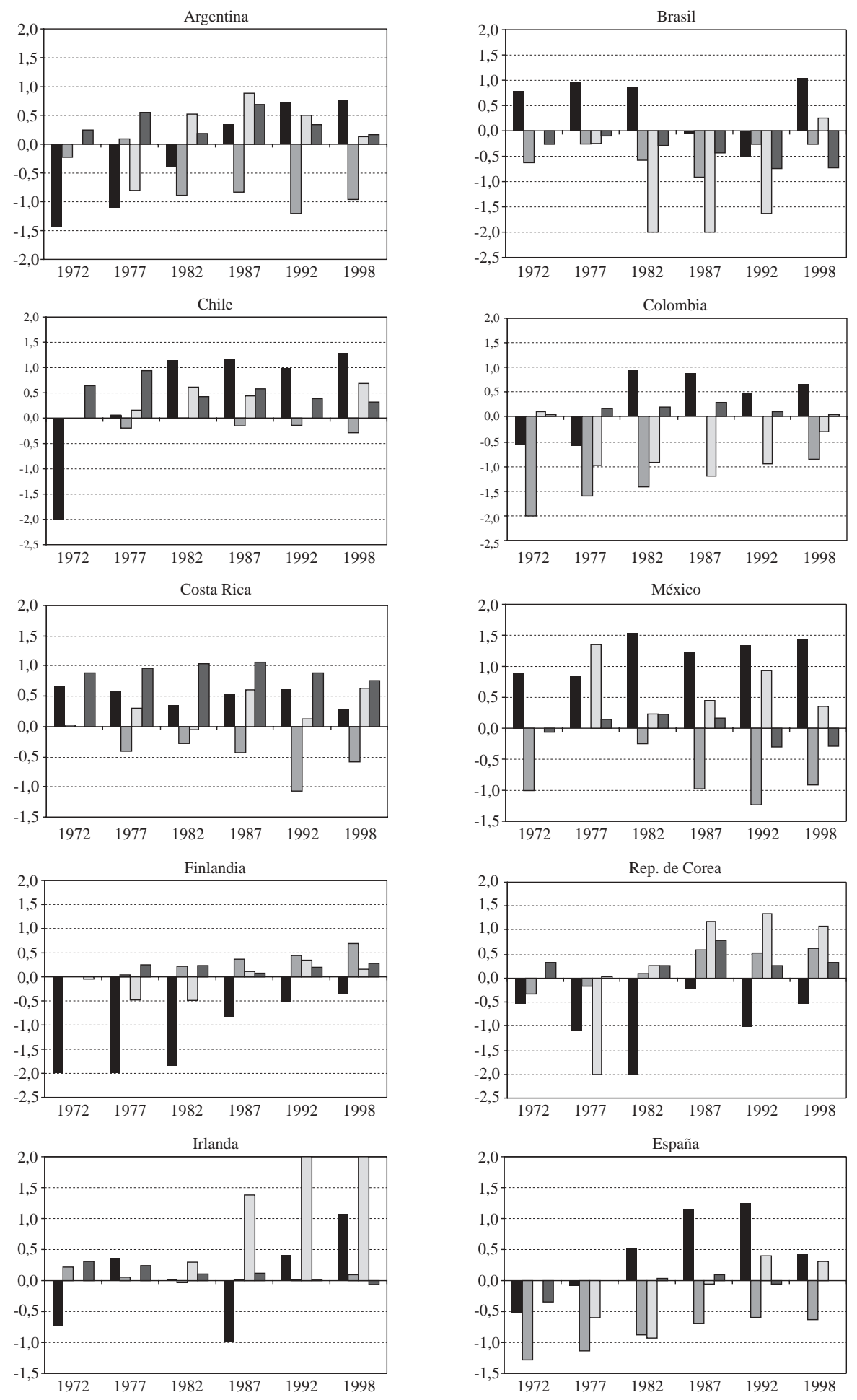

Fuente: Elaboración propia. 


\section{IV}

\section{La política de innovación \\ a mediano y largo plazos}

En vista de lo anterior, a mediano plazo hay que fomentar estos aspectos tal vez menos celebrados de la innovación. Benavente (2004) muestra que, de hecho, en Chile las innovaciones en procesos, diseño, organización, etc., son tan comunes como las innovaciones en el producto que suelen asociarse a la inversión en I+D (gráfico 3), lo que en cierto modo se asemeja a lo que encontramos en la OCDE. Sin embargo, el gráfico 4 indica que las cifras que efectivamente están invirtiendo las empresas de Argentina y Chile en actividades vinculadas a la innovación son muy reducidas con respecto al volumen de sus negocios. En el caso de Chile, la gran heterogeneidad de las empresas de un mismo sector revela que el aumento de la productividad de las que se sitúan lejos de la vanguardia puede influir de manera apreciable en el crecimiento de la productividad total de los factores. ${ }^{5}$

Por desgracia, no es mucho lo que sabemos sobre las razones por las cuales algunas empresas realizan estas innovaciones y otras no, o acerca de las políticas que las alentarían a efectuarlas. El sistema de centros tecnológicos de España ha sido fundamental para aumentar la capacidad de las pequeñas y medianas empresas (pyme) de agruparse, formar redes y realizar actividades de cooperación. El hecho de que tanto en España como en Italia haya empresas relativamente pequeñas que han logrado aumentar de manera importante la productividad señala que es preciso investigar más las limitaciones con que tropiezan estas empresas y qué políticas son eficaces para aumentar su "capacidad de absorción" de tecnología, esto es, la capacidad de utilizar y aprovechar la información disponible. Además, dadas las complementariedades de las reformas con la acumulación de capital, también habría que reexaminar las recomendaciones usuales de introducir reformas en materia de crédito, infraestructura, mercados de trabajo y otros aspectos, considerando en especial sus particulares consecuencias para la innovación.

\footnotetext{
${ }^{5}$ Para información sobre Chile, véase Bergoeing, Hernando y Repetto (2003). Por su parte, Chen y Dahlman (2004) han subrayado este punto.
}

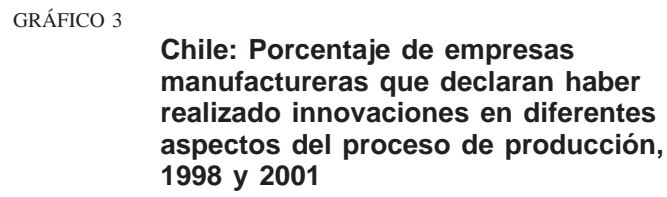

GRÁFICO 3

Chile: Porcentaje de empresas manufactureras que declaran haber realizado innovaciones en diferentes aspectos del proceso de producción, 1998 y 2001

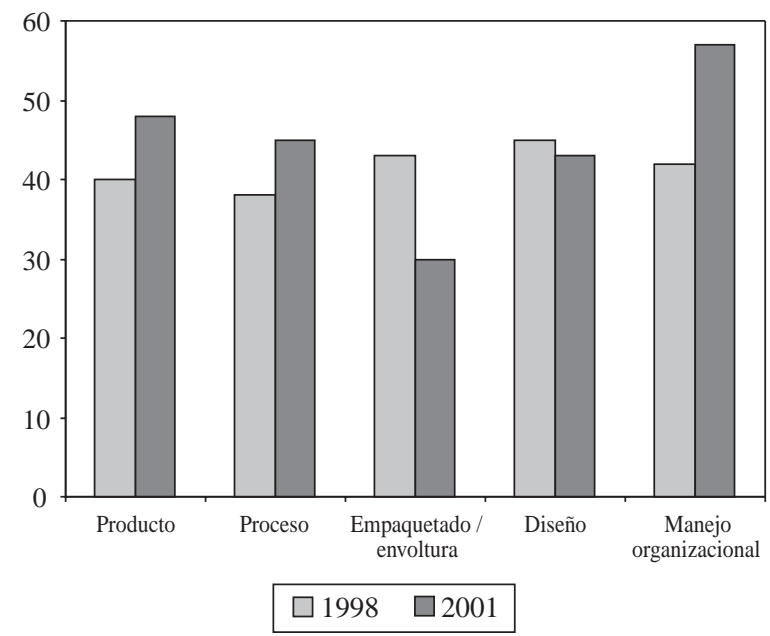

Fuente: Benavente (2004)

Además, es posible que un enfoque más creativo de la innovación pueda revelar nuevos campos de ventajas comparativas para la región. En Italia, las ventas de la industria de la moda superan las de la industria automotriz. En países como México y Colombia, en que hay una fuerte tradición en el diseño, tal vez se justifique invertir en estas áreas tanto como en ciencia y tecnología. En términos más generales, no se sabe a ciencia cierta qué elementos se necesitan para descubrir nuevos campos de ventajas comparativas del tipo en que hacen hincapié Hausmann y Rodrik (2003).

En lo que nunca podrá insistirse lo suficiente es en que, dado lo poco que se sabe acerca de la dinámica y las opciones de las empresas, hay que velar por que la demanda de innovación de cualquier tipo por parte de las empresas se mantenga en el centro del diálogo político, a fin de impedir que las inversiones en medidas por el lado de la oferta resulten infructuosas desde el punto de vista de la productividad o, peor aún, que tiendan a desviar la atención de los problemas realmente decisivos. 
GRÁFICO 4

Europa (promedio), y países europeos y latinoamericanos: Actividades relacionadas con la innovación, varios años

(Porcentaje del volumen de negocios)

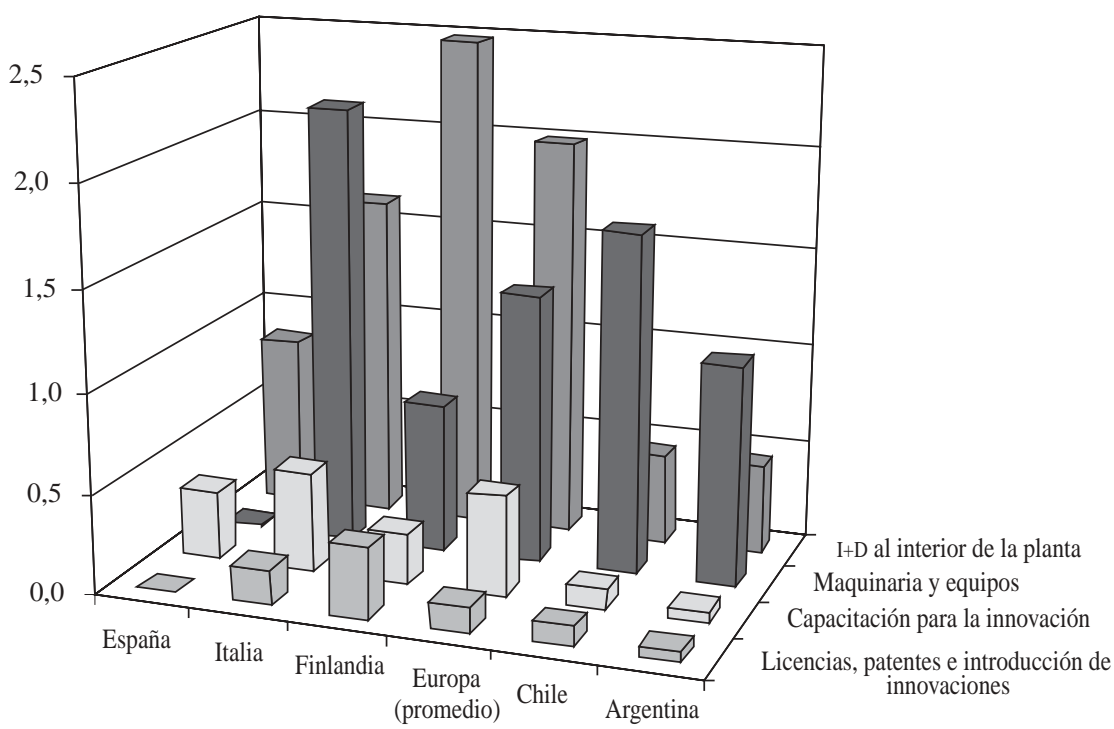

Fuente: Elaboración propia a partir de estudios sobre la innovación en las empresas en Europa y Chile.

En vista de lo anterior, la inversión en ciencia y tecnología y en I+D es importante ahora y parece ser esencial en el largo plazo para generar un crecimiento sostenido. En primer lugar, como inicialmente lo sostuvieron Cohen y Levinthal (1989), la I+D es fundamental no sólo para generar nuevos conocimientos, sino para mejorar la "capacidad de absorción" de las empresas. Esto significa que las políticas orientadas a mejorar la transferencia de tecnología no sirven de mucho a menos que la industria disponga de una masa crítica de capital humano de gran capacidad técnica, capaz de transformar los conocimientos nuevos en oportunidades de negocios. Además, la mayor parte de la transferencia tecnológica exige una significativa adaptación a los recursos locales y a las condiciones del mercado, para lo cual se necesita considerable I+D. En países avanzados como Francia, por ejemplo, la I+D no se orienta al desarrollo de productos o tecnologías "nuevos", sino a la transferencia y adaptación eficientes de nuevas tecnologías desarrolladas en otros lugares.

Segundo, la pérdida de dinamismo del desempeño de Italia y España observada últimamente sugiere que, aunque a mediano plazo América Latina debería dirigir la mirada a estos tipos más amplios de innovaciones; a largo plazo no se puede reemplazar la inver- sión en ciencia y tecnología, que es captada más adecuadamente por la I+D. Hace poco, el Economist otorgó a Italia, que en el último decenio ha registrado una tasa negativa de crecimiento de la productividad total de los factores, el título honorario de "enfermo europeo", en parte debido a su insuficiente capacidad científica y tecnológica. Preocupado del tema, España se ha empeñado en aumentar sus actividades de I+D y su cooperación con centros de investigación europeos. En el contexto del modelo de clubes de convergencia de Howitt y Mayer-Foulkes (2005), si España se limitara a adoptar tecnologías quedaría atrapado para siempre en un nivel de ingresos inferior al de aquellos países que, de hecho, inventan. ${ }^{6} \mathrm{Al}$ parecer, este escenario también pena a otros países con niveles medios "“condicionales" de I+D. A Dinamarca, Nueva Zelandia y a Australia y Canadá les preocupa cada vez más que esto los haya dejado como buenos adoptantes, pero con escasas posibilidades de mantenerse a la vanguardia del juego de la innovación, donde parecen obtenerse las grandes utilidades. Blömstrom, Kokko y Sjoholm (2002) sostienen que la aplicación de una lógica similar empujó

\footnotetext{
${ }^{6}$ Véase en Maloney (2002) una aplicación de esta tesis al bajo
} rendimiento de los recursos naturales en América Latina. 
GRÁFICO 5

Algunos países: Elasticidad de la creación de conocimientos, 1960-2000 (Porcentajes)

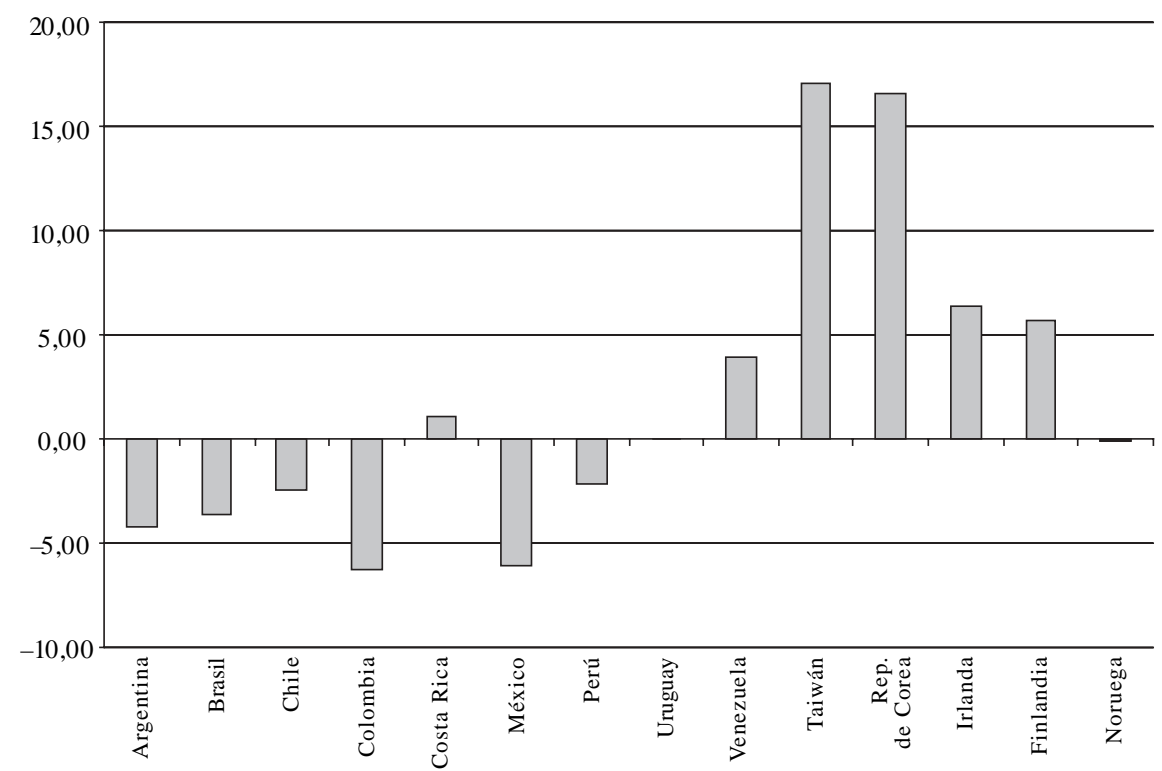

Fuente: Bosch, Lederman and Maloney (2004).

GRÁFICO 6

Algunos países: Evaluación subjetiva de la calidad de la investigación y del grado de cooperación, 2002

(Escala de respuestas de siete puntos)

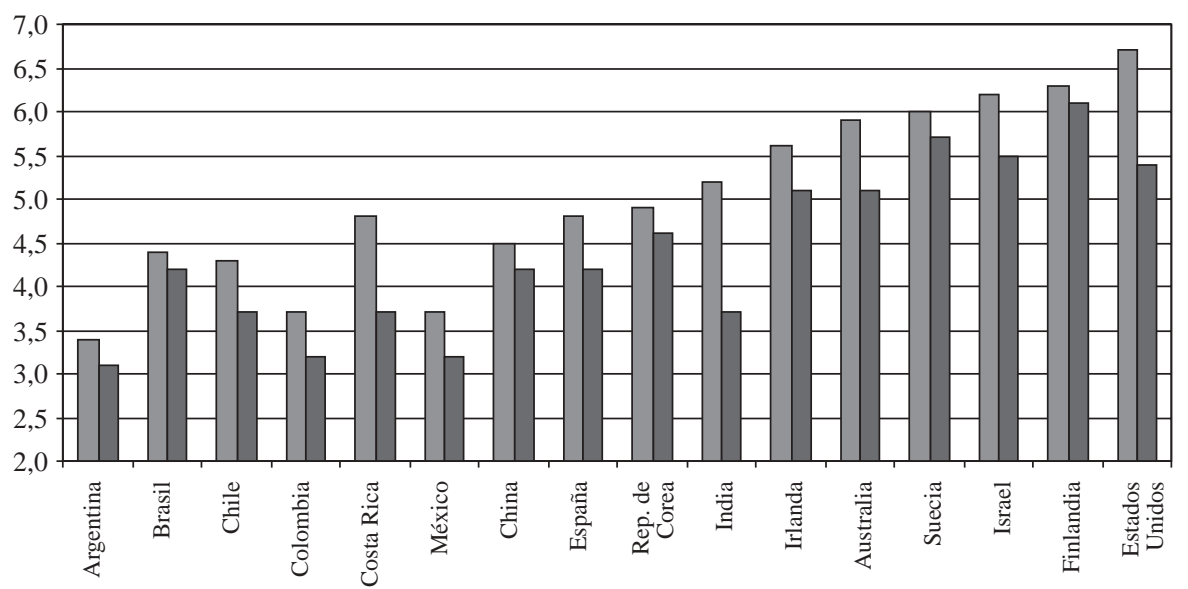

$\square$ Calidad de las instituciones científicas $\square$ Cooperación del sector académico/privado

Fuente: Foro Económico Mundial (2002).

a Singapur hacia una posición más focalizada en la generación de conocimientos que en la simple adopción de tecnología, como lo había hecho antes al aplicar el criterio más latinoamericano de depender de la inversión extranjera directa y de las licencias.
Para realizar un esfuerzo de esta naturaleza no solo se requiere tener más recursos, sino también usarlos con mayor eficiencia. En De Ferranti, Perry, Guasch y otros (2003) se sugiere que América Latina también va a la zaga en este aspecto. El gráfico 5 examina la eficiencia 
en la creación de conocimientos, utilizando las patentes como variable sustitutiva, y muestra que la elasticidad de las patentes respecto de la I+D es sustancialmente menor en los países latinoamericanos que en los otros países considerados. Como en los estudios microeconómicos las elasticidades generalmente giran en torno a 0,5 , pero en la OCDE se aproximan a la unidad, los resultados inferiores de los países latinoamericanos en el gráfico sugieren que la región no está en condiciones de aprovechar todo lo que podría los efectos indirectos del conocimiento. En el gráfico 6, las respuestas subjetivas de empresarios a preguntas del Foro Económico Mundial indican que, en una escala de siete puntos, los países latinoamericanos considerados obtienen calificaciones bastante mediocres res- pecto del grado de interacción entre el sector privado y los centros de investigación. A su vez, es posible que esto refleje la mala opinión que tiene generalmente el sector privado de los centros de investigación locales. ${ }^{7}$ Además, parece ser que en la región en su conjunto, alrededor de $60 \%$ de los recursos para I+D se destinan a la investigación básica (la cifra en los Estados Unidos es de $15 \%$ ) y que, contrariamente a lo que sucede en otros países más eficaces en este campo, el sector privado lleva a cabo o financia un porcentaje muy bajo de la I+D. Esto revela cierto desajuste entre los incentivos de las instituciones investigadoras y las necesidades de las economías locales, así como falta de alicientes para que las empresas privadas emprendan actividades de I+D.

\section{V}

\section{Políticas e instituciones concretas para el fomento de la innovación}

Como hasta ahora en la OCDE no hay un conjunto de mejores prácticas que pueda extrapolarse fácilmente a la situación de América Latina, en esta sección nos limitaremos a exponer algunas ideas surgidas de los estudios sobre el tema que podrían ser de interés para la formulación de políticas. ${ }^{8}$

1. Cómo enfrentar la apropiación y los efectos indirectos de la innovación: derechos de propiedad intelectual en contraposición a subsidios y crédito tributario

Los importantes efectos indirectos (secundarios) a los que podría dar lugar la innovación implican que la rentabilidad social es muy superior a la privada $\mathrm{y}$, por lo tanto, que las actividades innovadoras de las empresas, libradas a sus propios medios, serían subóptimas desde el punto de vista social, incluso si se eliminan las barreras y los desincentivos artificiales. Para abordar este problema se han utilizado dos tipos de instrumentos: los derechos de propiedad intelectual y los

\footnotetext{
${ }^{7}$ Las dos variables consideradas en el gráfico 6 parecen estar correlacionadas con la elasticidad de la creación de conocimientos, al igual que el nivel de educación y los derechos de propiedad intelectual (Bosch, Lederman y Maloney, 2005).

${ }^{8}$ Esta sección se basa en gran parte en Maloney (2005a).
}

subsidios fiscales (a través de recursos suministrados por el sector público, donaciones de contrapartida, crédito tributario).

Por lo general, el paso desde la actividad científica a los grandes avances tecnológicos y su desarro1lo, aplicación y difusión se ha concebido como un proceso lineal en el cual los efectos indirectos son mayores en la etapa científica del proceso que en la etapa de aplicación. Así, los subsidios públicos suelen concentrarse en torno a la investigación científica y tecnológica de nivel básico (que en muchos países se financia íntegramente con recursos públicos asignados a universidades e instituciones públicas de investigación) y a la utilización de derechos de propiedad intelectual "sólidos" en la parte del proceso que está más vinculada con la investigación aplicada, ya que estos derechos ayudan a resolver el problema de apropiación a expensas de la reducción de los efectos indirectos y de la difusión (los imitadores o usuarios ahora deben pagar un derecho de patente).

Romer (2005) y Rosenberg (2005) ${ }^{9}$ han sostenido que este criterio es errado, porque en la práctica hay

\footnotetext{
${ }^{9}$ Ambos trabajos fueron presentados a la Conferencia "R\&D and Innovation in the Development Process: A New Look at Theory, Evidence and Policies" (Banco Mundial/Universitat Pompeu Fabra, Barcelona, 9 al 11 de junio del 2005).
} 
una fuerte retroalimentación desde la etapa de aplicación a la de descubrimiento científico y tecnológico: muchos, si no la mayoría, de los grandes avances tecnológicos han surgido de intentos por resolver problemas de producción concretos, así como las cuestiones y problemas básicos que plantean estas actividades a la investigación científica y tecnológica de carácter más elemental. Por lo tanto, para estimular la I+D tecnológica aplicada conviene distribuir los subsidios públicos de manera más equitativa a lo largo del proceso, utilizando donaciones de contrapartida o créditos tributarios en la etapa de la investigación aplicada y dependiendo menos de la solidez de los derechos de propiedad intelectual. Esto se asemeja al debate sobre la eficacia relativa de los subsidios a la oferta y a la demanda que se da en otros campos: los subsidios no deberían orientarse exclusivamente a la oferta (la capacidad y las actividades científicas y tecnológicas de carácter básico), sino también a fomentar la demanda de innovación por parte de las empresas. ${ }^{10}$

Lo que hacen los autores citados, por lo tanto, es preguntarse si no sería tal vez ineficiente, desde el punto de vista sistémico, la orientación de los aspectos de los derechos de propiedad intelectual relacionados con el comercio (ADPIC), de la Organización Mundial de Comercio (омc). Dilucidar cuál sería el tipo de derecho de propiedad intelectual más apropiado para los países que se encuentran en una etapa de desarrollo similar a la de América Latina es algo que escapa al alcance del presente trabajo. Al respecto hay numerosos estudios que pueden ser consultados. ${ }^{11}$

Cabe considerar aquí cuál es la eficiencia relativa de los créditos tributarios comparados con los subsidios directos (por ejemplo, en virtud de programas de financiamiento de contrapartida) para estimular la demanda de innovación de las empresas. Los argumentos en favor de otorgar créditos tributarios en lugar de subsidios directos para sufragar los gastos en I+D, apuntan a evitar conductas orientadas a la obtención de utilidades u otras fallas del gobierno al "elegir los mejores" mediante programas de subsidios. Sin embargo, los inconvenientes del crédito tributario son bien conocidos: i) no es proporcional a la diferencia entre la rentabilidad social y la privada, como debería serlo, sino al costo de la I+D; ii) en la mayoría de los casos, es

\footnotetext{
${ }^{10}$ Para satisfacer su demanda de transferencia, creación o adaptación de tecnologías, las empresas pueden crear su propia capacidad de investigación científica y tecnológica, o contratar los servicios de universidades, centros de investigación u otras entidades.

${ }^{11}$ Véase, por ejemplo, Maskus (2000), Fink y Maskus (2005).
}

proporcional al costo anual total de la I+D y, aunque esto puede conducir a la ejecución de algunos proyectos de I+D marginales, gran parte de los recursos beneficiará a la I+D intramarginal, que se llevaría a cabo de todas maneras. En estos casos, los beneficios serán pocos en relación con el elevado gasto fiscal. Algunos países, como los Estados Unidos, han intentado establecer un crédito tributario progresivo para I+D, pero esto plantea grandes problemas de definición y medición de la base, y iii) crea un incentivo para clasificar artificialmente como gastos de I+D algunos otros que no corresponden a este rubro, lo que puede ser difícil de fiscalizar por las autoridades tributarias, sobre todo en países en desarrollo de escasa capacidad técnica y administrativa.

Algunos estudios han llegado a la conclusión de que en los países de la OCDE el crédito tributario efectivamente aumenta la I+D privada, pero no han efectuado un análisis de costo-beneficio. En la mayoría de los países latinoamericanos, cuyo sistema tributario contempla una serie de exenciones, créditos y resquicios y que poseen escasa capacidad administrativa, el costo fiscal difícilmente sería pequeño comparado con los posibles beneficios. Es posible que solo países como Chile y Brasil, que han demostrado ser capaces de hacer cumplir con alguna eficacia la legislación tributaria, estén en condiciones de experimentar con este mecanismo. A estas alturas, no lo recomendaríamos para la mayoría de los países latinoamericanos y caribeños.

En cambio, al comienzo los esfuerzos podrían orientarse a mejorar el diseño de los programas de subsidios ya existentes en muchos países de la región, con lo cual esos programas podrían superar los problemas señalados, y a la vez servir para promover tanto la cooperación entre empresas y universidades o centros de investigación como con la I+D que llevan a cabo estos últimos en relación con los bienes públicos (salud, medio ambiente y otros). En algunos países los programas han demostrado ser bastante eficaces, pero en otros parece haber mucha duplicación de esfuerzos y falta de criterios de eficiencia. ${ }^{12} \mathrm{Al}$ examinar los resultados de distintas experiencias exitosas realizadas en el ámbito mundial, surgen algunas pautas sobre la forma de maximizar sus posibles beneficios, mitigando al mismo tiempo el riesgo de que haya captación de utilidades y fallas del gobierno:

\footnotetext{
${ }^{12}$ Véase Sanguinetti (2004) para Argentina y Benavente (2004) para Chile.
} 
i) Ante todo, está el problema de gobernabilidad: ¿quién regula y administra el sistema? Para reducir la probabilidad de fallas del gobierno o de captación de utilidades y para asegurar la viabilidad comercial, convendría incluir al sector privado - a través de asociaciones comerciales amplias-y al mundo académico. Dado que en la mayoría de los países de América Latina y el Caribe la comunidad científica y tecnológica es pequeña y que en muchas materias no se encontrará a la vanguardia del conocimiento, en campos de actividad específicos la aprobación debería encomendarse a comités de expertos que incluyan a especialistas extranjeros. Incluso la Agencia tecnológica nacional (TEKES) de Finlandia, país que actualmente está a la cabeza de la creación tecnológica en muchos campos, acostumbra visitar el Instituto de Tecnología de Massachusetts (MIT) y la Fundación Nacional de Ciencias (SNF) de los Estados Unidos y otros centros mundiales de conocimiento avanzado a fin de mantenerse al tanto de las nuevas tendencias de la investigación tecnológica.

ii) El problema del monto del subsidio. Teóricamente, convendría que fuera proporcional a la diferencia entre la tasa de rentabilidad social y la de rentabilidad privada. Tal vez convendría establecer desde el inicio un rango para la contribución de contrapartida respecto del costo (de acuerdo con algunas estimaciones, para ser eficaz debería situarse en torno al $50 \%$ o más del punto de referencia usual de la OCDE) y en algunas materias dejar la clasificación de las propuestas (con distintas tasas de subsidio) a criterio de los expertos y de las autoridades revisoras competentes, una vez que evalúen cuáles serían los efectos indirectos respecto de los costos. Sistemáticamente, podría asignarse una proporción mayor de subsidio a algunos tipos de investigación (sobre bienes públicos, investigación tecnológica básica que podría tener una amplia gama de aplicaciones). Alternativamente, se ha sugerido no establecer el monto del subsidio por la vía administrativa (Link y Scott, 2004) sino mediante licitación pública, para garantizar que se logre la rentabilidad crítica, pero que no se la exceda mucho. Sin embargo, en el mejor de los casos este solo podría ser uno de los criterios de selección, ya que de lo contrario se tendería a preferir proyectos en que no hubiera una gran diferencia entre la rentabilidad social y la privada.

iii) El problema de la asignación de recursos a las distintas áreas o la promoción de áreas "estratégicas". Algunos países muy exitosos, como Finlandia, han preferido concentrar el apoyo en algunos ámbitos ge- nerales en los que ya existe algo de capacidad y actividad y en los cuales se considera que el país es competitivo (para evitar la elección sesgada de ganadores y a la vez la dispersión de los recursos y de la capacidad de evaluación entre demasiados proyectos). Por lo tanto, tal vez convendría dar prioridad (en igualdad de condiciones), o preasignar parte de los recursos, a un número reducido de áreas amplias bien seleccionadas que han revelado tener ventajas comparativas (por ejemplo, según el coeficiente de exportaciones y el dinamismo exportador) o en las cuales hay razones fundadas para estimar que pueden desarrollarse dichas ventajas. Con todo, habría que reservar algunos recursos para la competencia "abierta", ya que el surgimiento de actividades o productos de exportación no tradicionales puede ser bastante decisivo para el desarrollo (Hausmann y Rodrik, 2003). Además, en el caso de algunas áreas cruciales vinculadas a bienes no transables, que tienen importantes características de bien público (como la salud en las zonas tropicales), también podrían calificarse de antemano de estratégicamente prioritarios algunos problemas relacionados con el medio ambiente y la infraestructura. En todo caso, hay que tratar de evitar que las asignaciones sectoriales se conviertan en fuente de captación de utilidades para los grupos empresariales o académicos.

iv) Dada la importancia de estrechar los lazos entre las universidades, los centros o institutos de investigación y las empresas de América Latina, podría dársele prioridad a las propuestas que contemplen fórmulas de cooperación. Además, en vista del escaso aporte que hacen actualmente las empresas en gran parte de la región, podría otorgarse alguna prioridad a las propuestas presentadas y financiadas en parte por empresas productivas. También podría priorizarse la participación de las pymes. De esta manera se podría sumar puntos a la selección final, pero los criterios predominantes deberían ser la "solidez y capacidad técnicas" y la "relevancia y posibles efectos secundarios". En Chile, la Corporación de Fomento de la Producción (CORFO), la Comisión Nacional de Investigación Científica y Tecnológica (CONYCiT) y la Fundación Nacional para la Innovación Agraria (FIA) iniciaron recientemente un programa especial para fomentar estas formas de cooperación.

v) Por último, dada la importancia que revisten la experimentación y el conocimiento en esta materia, habría que establecer desde la partida minuciosos sistemas de vigilancia y evaluación. 


\section{El papel de las universidades y de las institu- ciones de investigación del sector público}

Dado que la capacidad para emprender actividades de I+D de importancia requiere una masa crítica y que los efectos indirectos pueden ser mayores a nivel de la investigación científica y tecnológica básica (en el área de los bienes públicos, por ejemplo), las instituciones especializadas en ciencia y tecnología claramente tienen un papel que desempeñar. No es sorprendente que estas instituciones de I+D no vinculadas con el mercado se hayan desarrollado en todas partes. Debido al alto grado de sinergia y las relaciones recíprocas que existen en el mundo moderno entre la innovación y las destrezas especializadas, a menudo los centros de investigación forman parte de las universidades o están vinculados a ellas. De hecho, la mayor parte de la I+D que se lleva a cabo hasta ahora en los países de América Latina (como ya se dijo, una proporción quizá excesiva) corresponde a estas entidades, especialmente las universidades, que por desgracia están totalmente aisladas del sector productivo y demasiado concentradas en la investigación básica. En especial, gran parte de las investigaciones relacionadas con la agricultura y los recursos naturales la efectúan los institutos de investigación del sector público, con dispares resultados (De Ferranti, Perry, Lederman y Valdés, 2004). El principal problema que hay que abordar es, entonces, cómo aumentar la cooperación entre esas instituciones y el sector productivo y cómo estimular investigaciones tecnológicas aplicadas más relevantes. A continuación se ofrecen algunas pautas derivadas de experiencias que han tenido resultados satisfactorios:

i) El financiamiento de la investigación que realiza este tipo de organismos debería obtenerse cada vez menos por asignación de recursos y cada vez más por competencia. Esto ya está sucediendo en algunos países de la región.

ii) Sin embargo, dada la necesidad de mantener una masa crítica en materia de ciencia y tecnología y alguna continuidad, es necesario equilibrar el financiamiento básico (cuyo monto debería revisarse periódicamente en función del desempeño) y el financiamiento competitivo de programas y proyectos mediante las donaciones de contrapartida antes analizadas. Como lo demuestra la experiencia de Nueva Zelandia y como parece haber sucedido en los últimos años con la reforma de la investigación agrícola en algunos países latinoamericanos, es posible que se vaya demasiado lejos en el financiamiento competitivo de programas y proyectos. El Centro de investigación tecnológica VTT de Finlandia combina un 25\% de financiamiento básico a los institutos de investigación con casi $25 \%$ de financiamiento privado y alrededor de $50 \%$ de donaciones de contrapartida de la Agencia tecnológica nacional TEKES.

iii) La estructura de los incentivos que se otorgan a los investigadores es fundamental; tanto la promoción como las recompensas deberían depender de los resultados. La forma en que se asignan los derechos de propiedad intelectual también es importante: aunque las universidades e institutos puedan conservar parte de los derechos de patente que se obtengan (como recompensa por los riesgos en que incurren al apoyar y financiar parcialmente las investigaciones), la mayor parte de ellos debería entregarse a los propios investigadores. Igualmente fundamental es la distribución de los derechos de propiedad intelectual entre empresas, universidades e investigadores en el caso de la I+D contratada por las empresas o realizada en virtud de acuerdos de cooperación. Hasta ahora, en América Latina no se ha avanzado mucho en esta materia, contrariamente a lo sucedido hace tiempo en Estados Unidos con la Ley Bayh-Dole, ${ }^{13}$ cuya evaluación ha sido en general positiva (si bien no del todo concluyente).

iv) También es importante la infraestructura, como laboratorios y oficinas de transferencia de tecnología. Estas últimas tienen por objeto crear redes de asociados industriales, establecer directrices para la comercialización del resultado de las investigaciones y administrar los derechos de propiedad intelectual de las universidades, parques científicos y semilleros. Numerosas universidades latinoamericanas han comenzado a crear esta clase de dependencias y les han encomendado algunas de estas funciones, pero aún son pocas las verdaderamente eficaces.

iv) Debería fomentarse todo tipo de vínculos entre las empresas y las universidades e institutos de investigación (no sólo en relación con la I+D): pasantías, capacitación profesional, servicios de asesoramiento y consultoría. Algunas universidades de América Latina también han empezado a avanzar con energía en esa dirección, especialmente en países en que hay más competencia entre las universidades públicas y privadas.

v) Finalmente, la gobernabilidad y la cultura son un elemento clave. Al respecto, la participación del sector privado en las juntas directivas y comités de universidades e institutos de investigación podría ser de gran utilidad. Sin embargo, es posible que muchas

\footnotetext{
${ }^{13}$ Enmienda de la Ley de Patentes y Marcas de 1980.
} 
universidades latinoamericanas tengan un sesgo cultural básico derivado del concepto humanista más monástico que prevalece en Europa continental, el que se manifiesta en cierta renuencia a intervenir en "asuntos mundanos" y a desempeñar un papel más práctico, especialmente como asistentes de la industria. Para superar esta situación se requiere un profundo debate nacional en torno al papel y cometido de las universidades.

\section{Otras instituciones especializadas}

Dentro del sistema nacional de innovación hay otras importantes funciones que requieren de instituciones especializadas públicas, privadas o mixtas que se desempeñen como "intermediarios honestos" carentes de intereses directos en los resultados (Link y Scott, 2004). Las más importantes de esas funciones son las siguientes: ción.

i) Promulgación, adopción de normas y certifica-

ii) Servicios de extensión para transferir tecnologías y técnicas de gestión, especialmente en sectores como la industria liviana y la agricultura, en los cuales el tamaño predominantemente reducido de las operaciones implica una menor capacidad de aprovechar los beneficios de la adopción de tecnologías y un acceso más limitado al crédito y la información.

iii) Coordinación y facilitación de actividades de cooperación en I+D que reúnan a la industria, el gobierno y las universidades en proyectos de investigación subsidiados por el gobierno, así como fiscalización de las investigaciones con financiamiento público o subsidiadas por el sector privado.

iv) Identificación - a modo de antenas internacionales- de las nuevas tendencias en materia de tecnología y de I+D, y fomento de la cooperación con instituciones internacionales en materias específicas.

En América Latina y el Caribe hay numerosas instituciones que desempeñan las funciones mencionadas en los incisos i) y ii), aunque no siempre lo hacen con eficacia. La Fundación Chile es un muy buen ejemplo de institución que cumple con éxito las funciones mencionadas en los incisos ii), iii) y iv), pero ha resultado difícil duplicarla con buenos resultados en otros países de la región.

\section{Aglomeraciones de empresas en torno a la in- novación (innovation clusters)}

Como los efectos indirectos de la innovación (y del aumento de capacidad) a menudo llegan solo a un sector o a un grupo de empresas relacionadas entre sí (incluidos proveedores, distribuidores y usuarios), lo más aconsejable es adaptar y centrar parte del apoyo a la política de innovación en las aglomeraciones de innovación que puedan aprovechar muchas de las economías externas del proceso innovador. Al parecer, la clave estaría en prestar apoyo a las aglomeraciones emergentes (en las que el sector privado ha tomado la iniciativa) en vez de tratar de crearlos desde la nada.

El sistema nacional de innovación puede incluir de manera eficiente algunos sistemas sectoriales de innovación. Sin embargo, la política de aglomeraciones sectoriales puede complementar pero no sustituir un sistema nacional de innovación eficiente, pues este debe facilitar el surgimiento de industrias que no figuran en los marcos de referencia de los gobiernos. Israel y Finlandia parecen haber logrado un buen equilibrio entre un sistema de innovación global sólido y eficiente y varias aglomeraciones sectoriales complementarias.

Las aglomeraciones deberían ser más que nada mecanismos de cooperación eficaz entre los sectores público y privado para resolver fallas del mercado y de coordinación, y no apuntar solo a la innovación y el perfeccionamiento de las destrezas. Pueden ser de suma utilidad para identificar los obstáculos y las fallas de coordinación relacionadas con el abastecimiento, la infraestructura (particularmente de transportes), la comercialización, la atracción de inversión extranjera directa y otros aspectos. Sin embargo, también pueden dar lugar a conductas orientadas a la obtención de utilidades (favoreciendo el proteccionismo y los subsidios ineficaces o desiguales) o a un desarrollo artificial y costoso de los proveedores locales. En especial, el estímulo a las aglomeraciones "verticales", que en el pasado fueron clave en muchos países, puede conducir a resultados muy ineficientes en el mundo actual, que se caracteriza por la mayor rapidez y menor costo de las comunicaciones y el transporte y una mayor integración internacional de la producción dentro de las cadenas productivas (De Ferranti, Perry, Lederman y Maloney, 2002).

\section{Los contactos internacionales}

Debido a que la mayor parte del desarrollo de tecnologías nuevas (y de otras innovaciones) seguirá dándose a nivel internacional (y, de hecho, en un número reducido de países, empresas transnacionales y centros de excelencia), es muy importante que el sistema nacional de innovación sea altamente internacional. Los 
vínculos internacionales entre empresas,,${ }^{14}$ entre universidades, y entre empresas locales y universidades extranjeras, son esenciales y deberían ser estimulados por las políticas de innovación.

La circulación internacional de las mejores mentes es de trascendental importancia para que los sistemas nacionales de innovación funcionen con eficacia, puesto que gran parte de la transferencia de conocimientos y de la cooperación en materia de innovación aún depende de las personas y de los contactos individuales. El aprendizaje en centros de excelencia y el trabajo en las empresas e instituciones que están a la vanguardia de la innovación o simplemente están más avanzadas que las entidades nacionales, pueden servir de catalizadores de la innovación y del cambio al regresar a sus países de origen. Por su parte, la contratación permanente o transitoria (mediante el intercambio institucional o de otra manera) de investigadores, técnicos, administradores y asesores comerciales extranjeros puede contribuir enormemente a estimular la innovación y el cambio. Por esta razón, los gobiernos, universidades, institutos de investigación y empresas deberían fomentar este tipo de intercambios. Los acuerdos inter- nacionales de inmigración transitoria (como el que discuten actualmente los Estados Unidos y México) y los avances logrados en la OMC respecto a la movilidad de las personas pueden ser parte importante de la dimensión internacional de las políticas de innovación.

Incluso el temido (e inicialmente costoso) éxodo de intelectuales puede ser convertido en una ventaja. Las diásporas ruso-judía, china, irlandesa e india han desempeñado un papel fundamental al respecto - así como en abrir el comercio y las oportunidades de inversión extranjera directa-, en Israel, China, Irlanda e India, respectivamente, y a menudo han sido activadas por la aplicación en esos países de políticas que generaron un clima muy favorable a la inversión, la innovación y el crecimiento. Algunos países de América Latina (gobiernos, sector privado e investigadores, ya sea en conjunto o a veces en forma independiente) han comenzado a organizar redes eficaces con sus nacionales calificados que han emigrado a los Estados Unidos, Europa y otras regiones, y a estimular su participación en distintas iniciativas públicas y privadas en sus países de origen. Este tipo de políticas podría dar provechosos resultados en el futuro.

\section{VI}

\section{Una vinculación hacia atrás con la equidad}

\begin{abstract}
Alejándonos un poco de la ciencia y la tecnología y acercándonos a una agenda de innovación más global, podemos establecer un vínculo hacia atrás con el tema de la equidad, y en términos más generales, con las importantes complementariedades del capital humano y otros tipos de capital relacionados con la innovación (De Ferranti, Perry, Guasch y otros, 2003).

Se piensa últimamente que la persistente desigualdad en la distribución de la riqueza en América Latina puede haber contribuido a reducir la capacidad de la región para adoptar tecnologías extranjeras. ${ }^{15}$ Engerman, Haber y Sokoloff (2000) sostienen que el período de crecimiento económico sostenido del siglo XVIII y principios del XIX que distingue a los Estados Unidos y Canadá de las demás economías del nuevo mun-
\end{abstract}

\footnotetext{
${ }^{14}$ Gran parte de la transferencia de la tecnología y la innovación se produce gracias a la interacción con proveedores y compradores extranjeros y al apoyo recíproco.

${ }^{15}$ Para mayores detalles, véase Maloney (2002).
}

do, obedeció fundamentalmente al patrón de colonización y de cultivos, que condujo a una distribución relativamente desigual del ingreso en las zonas de menor dinamismo. Esta concentración permitió que las elites favorecidas conservaran su influencia política y que quedara marginada gran parte de la población, por su menor acceso a licencias, recursos naturales, instituciones financieras y derechos de propiedad, así como a la educación básica.

La falta de acceso a la educación puede haber tenido especial importancia. La preocupación por el control social, la extrema desigualdad del ingreso, la insuficiencia de las finanzas públicas y tal vez un compromiso intelectual con un Estado pequeño, condujeron a que en América Latina se hicieran esfuerzos mucho menores por alcanzar la educación universal que en los países que llegaron a ser exitosos exportadores de recursos naturales. En 1870, más del 70\% de la población de 10 años o más en Australia, los Estados Unidos, Canadá y Suecia sabía leer y escribir, triplicando el 
porcentaje correspondiente a Argentina, Chile, Costa Rica y Cuba, y cuadruplicando el de Brasil y México. América Latina avanzó en forma desigual hacia estos niveles en los cincuenta años siguientes. En 1925, Argentina, Uruguay, Chile y Costa Rica alcanzaron tasas de alfabetización superiores a $66 \%$, mientras que México, Brasil, Venezuela, Perú, Colombia, Bolivia, Guatemala y Honduras se mantuvieron en $30 \%$ hasta mucho después (Mariscal y Sokoloff, 2000).

Como lo señalan Engerman y Sokoloff (1997, p. 287), esto tiene especial importancia porque la industrialización temprana reflejó el efecto acumulativo de los avances logrados individualmente a través de la economía, en vez de verse impulsada por los progresos logrados en una sola industria o por las actividades de una pequeña elite. Como una de las expresiones decisivas para el desarrollo de la innovación, afirman que la mayor igualdad del capital humano se explica en parte por las elevadas tasas de invención logradas en los Estados Unidos. Estos autores también sostienen que el interés más general por la posibilidad de obtener utilidades de las invenciones contribuyó a que se creara un sistema de patentes que, a la sazón, fue el más favorable del mundo para el común de la gente. Esto contrasta marcadamente con México y Brasil, donde los costos y la tramitación de las patentes limitaron su obtención a las personas adineradas o influyentes, y donde rara vez se otorgaba el derecho a organizar empresas e instituciones financieras, principalmente para proteger el valor de los derechos que ya estaban en manos de intereses poderosos.

Blomström y Kokko (2001) sostienen que en Suecia la introducción de un sistema de educación obligatoria en 1842 y el énfasis en la lectura y la aritmética fueron fundamentales para que las personas y las empresas aprendieran y adoptaran tecnologías nuevas: gran parte del aprendizaje básico y de la transferencia de tecnología se basó en instrucciones escritas, en la forma de planos y manuales. Esto también indica que el elevado número de estudios en que se compara a Argentina y Australia podría haber pasado por alto algo fundamental. Pese a que los autores australianos trasuntan un marcado sentimiento de "aquí estamos, por la gracia de Dios", está claro que a mediados del siglo XIX las tasas de alfabetización de Australia se aproximaban mucho más a aquellas de los países industrializados; esto, sucedía en un país que hasta el decenio de 1840 fue una colonia penal del Reino Unido. La historia de la Broken Hill Proprietary Company, Ltd. (BHP), compañía de alcance mundial fundada por un vigilante fronterizo de una estancia ovejera, demuestra la importancia de contar con una amplia base de personas letradas llenas de ideas y dispuestas a prestar apoyo a las instituciones.

En un trabajo reciente, Klinger y Lederman (2005) sugieren que ese tipo de efectos sigue siendo importante, y buscan explicar dos aspectos de la innovación. El primero es el descubrimiento, medido en términos de la introducción de nuevas industrias exportadoras como las promovidas por Hausmann y Rodrik (2003) y, segundo, el registro de patentes. El primero subestima la innovación en los países avanzados, debido a que ya cuentan con una estructura industrial bien establecida y habría que "inventar" exportaciones nuevas, mientras que el tema de las patentes subestima la actividad innovadora en los países pobres, donde sería más natural la difusión de las tecnologías existentes. Basándose en ambas medidas concluyen, como cabría esperar, que la población es un elemento determinante. Sin embargo, también influyen de manera importante la pobreza, el coeficiente de Gini de distribución del ingreso y la participación en la fuerza de trabajo de personas con educación secundaria. Esto puede interpretarse como un argumento para sostener que la población efectivamente innovadora es importante para generar nuevas ideas y crecimiento. En la medida en que América Latina redujo su población efectivamente innovadora al limitar la educación, la riqueza y el acceso a las instituciones a una elite relativamente pequeña, lo más probable es que se haya obstaculizado el crecimiento de la productividad total de los factores.

Además, en las sociedades cuyas elites hicieron gran hincapié en la teología y la filosofía (cuya expresión en el siglo XX podría ser la economía) y menospreciaron disciplinas aplicadas como la ingeniería, lo más probable es que el acceso dispar a la educación y la escasa movilidad social hayan restringido la oferta de trabajadores de clase media que en los países avanzados constituyeron la columna vertebral de las clases de inventores e ingenieros. Como muestra el cuadro 1,

CUADRO 1

Algunos países: Proporción de ingenieros a fines del siglo $\mathrm{XIX}$ y comienzos del siglo $\mathrm{XX}$

\begin{tabular}{lcc}
\hline País & Año & $\begin{array}{c}\text { Ingenieros por cada } \\
\text { cien mil trabajadores }\end{array}$ \\
\hline Australia & 1920 & 47 \\
Chile & 1930 & 6 \\
Colombia & 1887 & 8 \\
Estados Unidos & 1920 & 128 \\
Suecia & 1890 & 84 \\
\hline
\end{tabular}

Fuente: Maloney (2002). 
a fines del siglo $\mathrm{XX}$ era tajante la diferencia entre Colombia y Chile, por una parte, y Australia por la otra, en cuanto al número de ingenieros en la población. Las oportunidades perdidas de acumular apren- dizaje por la práctica condenaron a la región a una relación de dependencia respecto de los países avanzados, no solo en la invención de tecnología sino también en su difusión.

\section{VII}

\section{Conclusiones: la necesidad de una visión amplia}

Además de la brecha en materia de acumulación, los países de América Latina y el Caribe confrontan un problema relacionado con la innovación, que se manifiesta a la vez en la actividad innovadora dentro de diversos campos y en la forma en que ésta se transmite a otros actores de la economía. Al parecer la innovación merece entonces ocupar un lugar importante en la agenda política.

La política de innovación rebasa el campo de la política de ciencia y tecnología. Incluso si aceptamos que la insuficiente productividad total de los factores se debe solo al bajo nivel de avance tecnológico y no a ineficiencias, aún hay numerosos aspectos que abordar, tales como las barreras a la creación de más empresas innovadoras, la deficiente capacidad de absorción de las empresas, las barreras internas (la legislación laboral, por ejemplo) o de los mercados de crédito que impiden adoptar las tecnologías existentes, así como las deficiencias de la infraestructura científica y tecnológica y la falta de incentivos a la innovación. Para fomentar la innovación se requiere entonces una percepción más general de los factores que pueden impedirla y, por lo tanto, un conjunto más amplio de diagnósticos que los vinculados con la ciencia y la tecnología en sí. Para estimular la innovación en estos campos hay que centrarse en la capacidad y los incentivos de la empresa: desarrollar las destrezas empresariales y el gusto por la innovación, y enfrentar las barreras relacionadas tanto con la innovación como con la falta de ella y las deficiencias del mercado que impiden aumentar la productividad.

La capacidad de las empresas para ponerse al día en materia de tecnología desempeña un papel fundamental. Aunque los debates generalmente se dan a nivel global, el aumento de la productividad es un fenómeno que depende principalmente de las empresas. Si no hay demanda de innovación desde el sector pri- vado, los esfuerzos por mejorar la capacidad científica y tecnológica por el lado de la oferta serán infructuosos. Fundamentalmente, invertir recursos públicos para el bien público no se traducirá en un aumento de la productividad a menos que el sector privado asuma el papel que le corresponde.

El sector privado de los países de América Latina y el Caribe debe prepararse para esta transición. Aunque la composición de sus actividades innovadoras se asemeja a la de sus contrapartes europeas, los esfuerzos del sector privado son extremadamente reducidos, especialmente en lo que se refiere a capacitación y adquisición de conocimientos, pero también a I+D. Esto es preocupante sobre todo en el caso de las empresas de mayor tamaño, que supuestamente no están tan sujetas a restricciones de la información, del crédito y otras, y deberían hallarse a la vanguardia de sus sectores respectivos. El sector privado debe tomar conciencia de ello y aumentar sus intentos de innovación a fin de poder absorber los conocimientos generados en el sistema nacional de innovación y en el exterior.

Habrá que ir más allá de aumentar el acervo de capital humano calificado y de entidades de investigación para mejorar la difusión de conocimiento a este nivel. Datos de la OCDE indican que a nivel micro la generación de conocimientos tiene rendimientos a escala decrecientes, mientras que a nivel global dichos rendimientos son constantes. Esto apunta a que en la economía los conocimientos tienen apreciables efectos indirectos en las personas y las empresas. En el plano nacional, la creación de conocimientos tiene rendimientos decrecientes, lo que indica que posiblemente esos efectos sean menos frecuentes (Bosch, Lederman y Maloney, 2005). Por lo general, la magnitud de los efectos indirectos parece guardar relación con factores como el nivel de educación, la calidad de las instituciones de investigación, el grado de colaboración 
entre las instituciones de investigación y el sector privado, y la propiedad intelectual. Estos son aspectos fundamentales para el diseño de políticas en el contexto de un sistema nacional de innovación.

Los países de América Latina y el Caribe deben entonces comenzar por introducir las reformas necesarias para mejorar el funcionamiento del sistema nacional de innovación y sentar las bases para una plena participación en la comunidad científica y tecnológica internacional. Aunque hoy es posible aprovechar fuentes de crecimiento de la productividad menos inusuales, en la práctica puede tomar varias décadas reformar el sistema nacional de innovación y en especial lo relacionado con el sistema de ciencia y tecnología. Habrá que realinear los incentivos, crear las instituciones necesarias, reformar o desmantelar las que son ineficientes, e identificar las intervenciones que pueden dar buenos resultados. Y probablemente habría que comenzar a hacerlo ahora.

A la larga, es posible que las políticas en pro de la equidad estimulen el crecimiento, al allegar más gente al esfuerzo de innovación.
Benavente, J. (2002): The impact of public financing and research groups on innovative activities in Chilean industry, Washington, D.C., Banco Mundial, inédito.

(2004): Investigación y desarrollo, innovación y productividad: un análisis econométrico a nivel de la firma, Santiago de Chile, Universidad de Chile, inédito.

Bergoeing, R., A. Hernando y A. Repetto (2003): The effect of policy distortions on productivity dynamics, Santiago de Chile, Centro de Economía Aplicada, Universidad de Chile, inédito.

Blomström, M. y A. Kokko (2001): From Natural Resources to Hightech Production: The Evolution of Industrial Competitiveness in Sweden and Finland, Estocolmo, Stockholm School of Economics.

Blomström, M., A. Kokko y F. Sjoholm (2002): Growth and innovation policies for a knowledge economy: experiences from Finland, Sweden, and Singapore, Washington, D.C., Banco Mundial, inédito.

Bosch, M., D. Lederman y W. Maloney (2005): Patenting and Research and Development: a Global View, Policy Research Working Paper, $N^{\circ} 3739$, Washington, D.C., Banco Mundial.

Caballero, R., K. Cowan y otros (2004): Effective Labor Regulation and Microeconomic Flexibility, Cowles Foundation Discussion Paper, $\mathrm{N}^{\circ} 1480$, New Haven, Connecticut, Cowles Foundation for Economic Research.

Caselli, F. y S. Tenreyro (2004): Is Poland the Next Spain?, Discussion Paper 04-8, Boston, Federal Reserve Bank of Boston.

Cohen, W.M. y D.A. Levinthal (1989): Innovation and learning: the two faces of R\&D, Economic Journal, vol. 99, N 397, Londres, Royal Economic Society.

Comin, D. (2004): R\&D: A Small Contribution to Productivity Growth, NBER Working Paper, $\mathrm{N}^{\circ} 10625$, Cambridge, Massachusetts, National Bureau of Economic Research.

Chen, D. y C. Dahlman (2004): Knowledge and Development: A Cross-Section Approach, Policy Research Working Paper Series, $N^{\circ} 3366$, Washington, D.C., Banco Mundial.

De Ferranti, D., G. Perry, D. Lederman y W. Maloney (2002): De los recursos naturales a la economía del conocimiento: comercio y calidad del empleo, Washington, D.C., Banco Mundial.

De Ferranti, D., G. Perry, L. Guasch y otros (2003): Cerrando la brecha en educación y tecnología, Washington, D.C., Banco Mundial.

De Ferranti, D., G. Perry, D. Lederman y A. Valdés (2004): Más allá de la ciudad: la contribución del campo al desarrollo, Washington, D.C., Banco Mundial.

Engerman, S. y K. Sokoloff (1997): Factor endowments, institutions, and differentials paths of growth among new world economies: a view from economic historians of the United States, en S. Haber (comp.), How Latin America Fall Behind. Essays on the Economic Histories of Brazil and Mexico, 1800-1914, Stanford, California, Stanford University Press.

Engerman, S., S. Haber y K. Sokoloff (2000): Inequality, institutions, and differential paths of growth among new world economies: a view from economic historians of the United States, en C. Menard (comp.), Institutions, Contracts and Organizations, Northhampton, Massachusetts, Edward Elgar.

Fink, C. y K.E. Maskus (2005): Intellectual Property and Development: Lessons from Recent Economic Research, Washington, D.C., Oxford University Press/Banco Mundial.

Foro Económico Mundial (2002): The Global Competitiveness Report, 2001-2002, Ginebra.

Hausmann, R. y D. Rodrik (2003): Economic development as selfdiscovery, Journal of Development Economics, vol. 72, $\mathrm{N}^{\circ} 2$, Amsterdam, Elsevier, diciembre.

Howitt, P. y D. Mayer-Foulkes (2005): R\&D, implementation and stagnation: a Schumpeterian theory of convergence clubs, Journal of Money, Credit and Banking, vol. 37, $N^{\circ} 1$, Columbus, Ohio, Ohio State University Press, febrero.

Klinger, B. y D. Lederman (2005): Sectoral concentration in the search for innovations and export booms, Washington, D.C., Banco Mundial, inédito.

Lederman, D. y W. Maloney (2003): R\&D and development, Washington, D.C., Banco Mundial, inédito.

Link, A. y J. Scott (2004): The role of public research institutions in a national innovation system: an economic perspective, Washington, D.C., Banco Mundial, inédito.

Maloney, W. (2002): Missed opportunities: innovation and resourcebased growth in Latin America, Economia, vol. 3, $\mathrm{N}^{\circ} 1$, Washington, D.C., Brookings Institution Press.

(2005a): Innovation policies in Latin America: a guide to the background papers commissioned for innovation policies II, Washington, D.C., Banco Mundial, inédito.

(2005b): Patterns of innovation, Washington, D.C., Banco Mundial, inédito.

Maloney, W. y A. Rodriguez-Clare (2005): Innovation shortfalls, Washington, D.C., Banco Mundial, inédito.

Marimón, R. (2005): Innovation in Spain: past and future challenges, Washington, D.C., Banco Mundial, inédito.

Mariscal, E. y K. Sokoloff (2000): Schooling, suffrage, and the persistence of inequality in the Americas, 1800-1945, en S. Haber (comp.), Political Institutions and Economic Growth in Latin America. Essays in Policy, History and Political Economy, Stanford, Stanford University. 
Maskus, K.E. (2000): Intellectual Property Rights in the Global Economy, Washington, D.C., Instituto de Economía Internacional, Washington D.C

Meller, P. (2001): Chilean Copper: Facts, Role and Issues, Washington, D.C., Banco Mundial.

OCDE (Organización de Cooperación y Desarrollo Económicos) (2004): Science, Technology and Industry Outlook, 2004, París.

Pinto, A. (1959): Chile, un caso de desarrollo frustrado, Santiago de Chile, Editorial Universitaria.

Romer, P. (2005): The Arc of Science, documento presentado en la Conferencia
"R\&D and Innovation in the Development Process: A New Look at Theory, Evidence and Policies" (Barcelona, junio del 2005), inédito.

Rosenberg, N. (2005): Science and Technology: Which way does the causation run?, documento presentado en la Conferencia "R\&D and Innovation in the Development Process: A New Look at Theory, Evidence and Policies" (Barcelona, junio de 2005), inédito

Sanguinetti, P. (2004): Innovation and R\&D expenditures in Argentina: evidence from a firm level survey, Buenos Aires, Universidad Torcuato di Tella, inédito.

Wright, G. (2001): Resource Based Growth, Then and Now, Washington, D.C., Stanford University/Banco Mundial. 